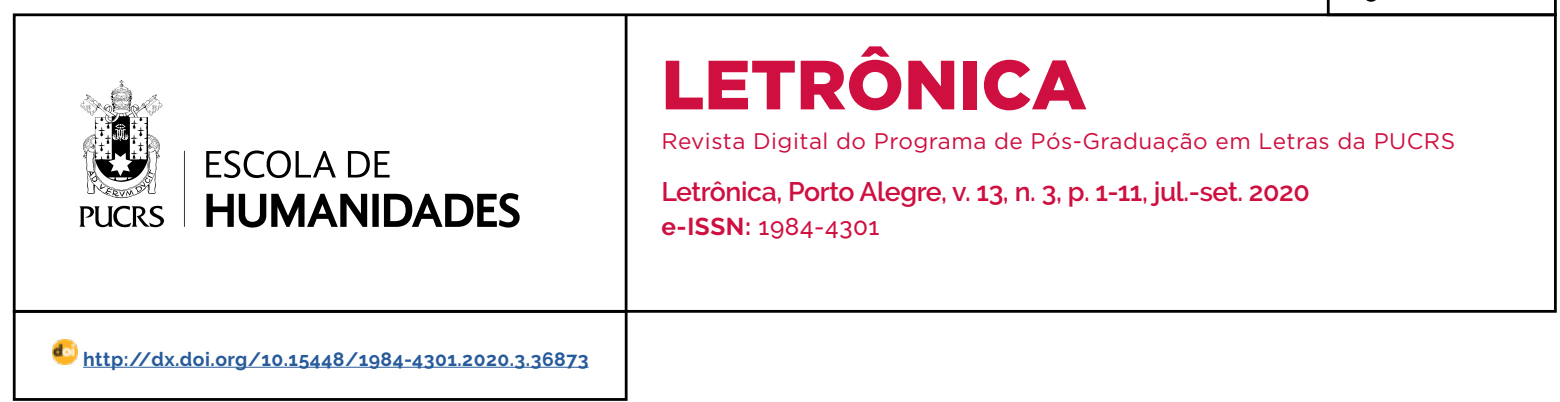

\title{
A literatura brasileira vista de longe ${ }^{\mathbf{1}}$
}

\section{Brazilian literature in a distant reading}

\section{Bruna Carolina de Almeida Salles ${ }^{2}$ orcid.org/0000-0003-3078-8524 brunespassis@yahoo.com.br}

Recebido em: $16 / 01 / 2020$. Aprovado em: 15/05/2020 Publicado em: 30/10/2020.

\begin{abstract}
Resumo: O artigo aborda, em perspectiva complementarmente contrária aos métodos tradicionais de análise da literatura brasileira, a difusão e a mobilização da produção literária brasileira modernista para outras paragens culturais, cujo resultado é o redesenho de fluxos da circulação de modelos literários e culturais. Em um primeiro momento, são abordados os meios de difusão da literatura brasileira em Portugal e na Europa, de modo geral; em seguida, a repercussão que ela tem, sobretudo, no ambiente acadêmico português; e, por fim, a adesão ao modelo literário brasileiro por parte dos literatos cabo-verdianos em meados do século XX. Palavras-chave: Literatura brasileira. Circulação. Repercussão. Distant Reading.
\end{abstract}

Abstract: The article approaches, in a complementary perspective, in a sense, contrary to the traditional methods of analysis of Brazilian literature, the diffusion and mobilization of the modernist Brazilian literary production to the other cultural places, which the result is the redesigning of flows of the circulation and cultural models. At first, the means of diffusion of the Brazilian literature in Portugal and Europe, in general, are approached; next, the repercussion that it has, above all, in the Portuguese academic environment; and, finally, the adherence to the Brazilian literary model by Cape Verdean literati in the middle of the twentieth century. Keywords: Brazilian literature. Circulation. Repercussion. Distant Reading.

"Um livro é uma força em marcha. Está melhor quando passa de mão em mão, do que quando dorme o sono egoístico das bibliotecas".

(Ribeiro Couto)

"I... este modo de trabalhar em que a distância não é um obstáculo, mas sim uma forma especifica de conhecimento. A distância faz com que se vejam menos os detalhes, mas faz com que se observem melhor as relações, os patterns, as formas".

(Franco Moretti)

\section{Introdução}

Partindo da conjuntura intelectual da primeira metade do século $X X$ no Brasil, que se constituiu em um importante período de redefinição da cultura e da literatura brasileiras em função do surgimento de novos intérpretes que foram responsáveis por redefinir a projeção da imagem nacional vinculada internacionalmente - e levando em consideração 
o momento no qual os contatos começavam a ganhar o impeto global hoje imperante -, este trabalho direciona seu interesse para uma abordagem pouco convencional nos estudos de literatura brasileira. Trata-se de perscrutar um fenômeno que é capaz de suscitar novas abordagens às quais a historiografia literária ainda não deu a devida atenção.

A virada do século XIX para o XX foi marcada, entre os intelectuais brasileiros, pelo anseio de reverter o sentimento de inferioridade em relação à cultura, à língua e à literatura portuguesas, buscando-se, para tanto, demonstrar as grandezas do país e as potencialidades da nação, ${ }^{3}$ de modo que, a herança da erudição lusitana passou por um gradativo processo de ressignificação (de dentro para fora) que eclodiu em alguns circulos intelectuais portugueses como verdadeiro ultraje, ${ }^{4}$ e cuja ofensa mais polêmica seria aquela sintetizada na negação do academicismo (definido pelas normas linguísticas de Portugal) pelas obras literárias modernistas, o que culmina em um importante conceito de diferenciação da expressividade literária brasileira, causando ainda um efeito de amplitude nas possibilidades expressivas da língua portuguesa tomada como instrumento de criação.

Assim, no contexto de profundas mudanças e reinterpretações das culturas ocidentais que mobilizava os intelectuais interessados em transformar ou alterar o status quo da cultura brasileira em uma dimensão internacional, essas alterações corroboraram o reposicionamento dos intelectuais brasileiros frente à emergência de uma nova conjuntura, já que a urgência da dissolução do antigo mundo imperialista acabava por desafiar as certezas construidas pelo continente europeu, as quais foram sendo realçadas pela ascensão de novos prismas histórico-culturais surgidos no decorrer do século $X X$, na esteira dos quais se conforma o pensamento pós-colonial.

No que concerne ao Brasil e às tendências intelectuais que se fizeram sentir no início do sé- culo, em fins dos anos 1920, no âmbito da Primeira Guerra Mundial, um dos fatores que mais afetaram a esfera cultural brasileira foi a crise da importação. Tal como observa Laurence Hallewell em O livro no Brasil (2005), a escassez do livro importado favoreceu o desenvolvimento do mercado livresco nacional, criando condições para uma substituição sistemática do livro europeu pelo livro brasileiro.

Nesse âmbito, atribui-se ao empreendedorismo do editor José Olympio a essencial diversidade e o alcance massivo que o livro alcançou, o que contribuiu de forma crucial para a composição de um cenário intelectual nacional do qual emergia um quadro de autores interessado na sistematização do conhecimento sobre o país.

Quanto ao primeiro aspecto, Hallewell (2005) destaca a diversificada gama de intelectuais, de diferentes ideologias, que compôs o quadro de autores da editora, afirmando que cerca de 80\% dos escritores mais importantes da época publicaram suas obras pela casa editorial de José Olympio (HALLEWELL, 2005, p. 476). O segundo aspecto se deve à ampliação do número de tiragens convencionalmente praticado pelas editoras da época, mudança logística que colocou em circulação um grande número de obras literárias e interpretativas com o sinete da Livraria José Olympio Editora.

Nesse processo, na medida em que se consolidava o campo do mercado editorial brasileiro, também ganhava força o campo intelectual por ele amparado. A qualidade dessas publicações (advinda do conhecimento e dos investimentos que José Olympio concentrou na produção livresca nacional) e o impacto que elas causavam na sociedade brasileira colocavam em evidência a postura dos escritores e o conteúdo das obras nacionais.

Ressalte-se que, nesse periodo, o país vive as transformações do governo populista de Getúlio Vargas, cujo programa empreende um massivo plano de alfabetização nacional que se coaduna aos interesses tanto do mercado editorial quanto da classe intelectual. Essa tripla demanda (merca-

\footnotetext{
3 Como mostra a análise de Tânia Regina de Luca (1999) sobre uma das revistas que melhor sintetiza esse anseio: a Revista do Brasil. 4 Arnaldo Saraiva (2004) trata da recepção desse discurso brasileiro em Portugal, diferenciando circulos de apoiadores e opositores aos novos escritores brasileiros.
} 
dológica, intelectual e social) é responsável pelo processo de "unificação cultural" a que se refere Antonio Candido no ensaio "A revolução de 30 e a cultura" (2006). Por isso, não é mera coincidência que o auge da produção romanesca modernista tenha se dado justamente na década mais emblemática da história do livro brasileiro. Trata-se, antes, de uma imbricação entre campos de cooperação sistemática que merece estudos mais dedicados.

Esse clima de efusão intelectual colocou as questões brasileiras em foco e a grande quantidade de obras em circulação disseminou-as pelo País. O escritor e diplomata Ribeiro Couto, em artigo intitulado "O instinto do Brasil", publicado no jornal A província, em 10 de fevereiro de 1929, faz referência ao espírito que paira sobre ele, mesmo residindo no então conturbado continente europeu:

[...] Eu chamo de instinto do Brasil esse estado de permanente vigilia em que vive a minha sensibilidade nacional. Essa ternura confusa e sem regra, esse misticismo abortivo que às vezes se exalta em reações e vagos projetos, essa realidade fragmentária e interior que impõe a permanente presença de imagens familiares, de amigos, de paisagens, de aspectos, de cidades, de acontecimentos, de tudo que "está no Brasil" (COUTO, 1929). ${ }^{5}$

A centralidade do Brasil nas preocupações intelectuais e artísticas desse período confere uma nova dimensão à percepção dos escritores brasileiros. A "sensibilidade nacional" da qual fala Couto enaltece um sentido que é caro à época: sentir o espaço e as relações como aspectos autênticos da formação do caráter nacional, de modo que falar de si é, em parte, falar de seu próprio país como algo instintivo ou imanente.

Mas o que é particularmente relevante nesse discurso é o dado externo a ele: o fato de o escritor estar no estrangeiro. É justamente a conciliação entre as preocupações nacionais e seu itinerário fora do Brasil, o que o leva a atuar como um intermediário (ou transfert culturel, para usar a nomenclatura de Michel Espagne (1994, p. 121)), em um projeto pessoal e empenhado para colocar as obras brasileiras em circulação internacional.

Também a razão de ser da postura de Couto encontra respaldo no clima intelectual que a editora de José Olympio, de cujo rol de escritores ele fazia parte, havia instaurado no País. Ao analisar a dinâmica da Livraria José Olympio Editora, em "A arte da amizade: José Olympio, o campo do poder e a publicação de livros autenticamente brasileiros" (2011), Gustavo Sorá trata de como:

As rodas de intelectuais formavam um sistema
de produção e circulação cultural, cuja dinâ-
mica era central para a evolução das práticas
intelectuais e editoriais do inicio dos anos 1930.
Em uma época em que a figura do distribuidor
era inexistente, as políticas nacionais de edu-
cação estavam sendo instauradas e a manu-
tenção de filiais de editoras só começavam a
ser possíveis para editores de livros didáticos.
[...] Dinâmica semelhante ao catálogo José
Olympio também se verifica com representan-
tes de circulos intelectuais de Minas Gerais e
São Paulo (SORÁ, 2011, p. 58-59, grifo do autor).

Tomando a afirmação de Sorá como parâmetro das relações que colocaram em circulação um grande corpo de obras nacionais no Brasil, procuramos aventar a ideia de que esse sistema pessoal - criado para atender propósitos internos - tenha se espraiado para outros pontos geográficos que acabaram por dinamizar a produção literária brasileira (e seus modelos) para novos contextos de recepção.

Desse modo, as necessidades internas de distribuição do livro acabaram por enredar os escritores em uma teia de contatos ${ }^{6}$ que ultrapassou as fronteiras brasileiras para integrar um sistema maior de trocas que corresponderam a necessidades diversas. Há que se ressaltar que essa transposição só foi possivel mediante o posicionamento dos escritores brasileiros em lugares que deram impulso e novo vigor à circulação dessas obras.

Em outro artigo publicado no Jornal do Brasil, em uma coluna intitulada "Projeção literária do Brasil no Estrangeiro", mantida por Ribeiro Couto no período de sua estada no velho continente, o diplomata das letras brasileiras afirma: 
No meu artigo de quinta-feira, tratei da necessidade que temos, de promover e animar as traduções de obras brasileiras para os principais idiomas, a fim de mostrarmos aos outros povos que à beira desse mar não há somente alguns coqueiros e algumas povoações exóticas, como pensam certos viajantes. Com a mais inteira boa fé e desinteresse, venho, há uns cinco ou seis anos, fazendo alguma cousa por minha própria conta e risco em favor desse movimento (COUTO, 1933).?

O excerto extraído de "Técnica da ilusão" (16/04/1933) corrobora o caráter pessoal que respaldou essa atividade e a intenção do escritor em agenciar essa circulação com o intuito de promover o conhecimento do Brasil a partir das obras postas em movimento.

\section{A repercussão no meio intelectual e acadêmico português}

Em seu trabalho seminal a respeito das relações intelectuais entre portugueses e brasileiros (Modernismo brasileiro e modernismo português: subsidios para o seu estudo e para a história das suas relações), Arnaldo Saraiva (2004) observa o dualismo sob o qual a recepção das obras modernistas brasileiras se fez sentir em Portugal.

Como demonstra o autor, a virada do século XIX para o XX significou um importante momento para a negociação da autonomia cultural brasileira no meio intelectual e acadêmico lusitano, ${ }^{8}$ cujo marco pode ser historicamente apontado pela criação de um lugar de visibilidade junto à universidade para os estudos brasileiros:

A necessidade de oficializar em Portugal os estudos sobre a história, a geografia, e a cultura do Brasil faziam-se sentir mais intensamente desde que os estudantes brasileiros começaram a frequentar menos as universidades portuguesas; desde que a emigração portuguesa no Brasil passou de algum modo a ter de competir com outras; ou desde que o Brasil começou a manifestar alguma autonomia cultural e começou a ser reconhecido como uma "grande nação", no virar do século XIX para o século XX quando surgiu também o fenômeno do "ufanismo".
Mas o gesto decisivo para a criação e funcionamento na Universidade de Lisboa de uma cadeira de Estudos Brasileiros só seria feito em 1915 pelo poeta português Alberto de Oliveira (SARAIVA, 2004, p. 41).

Essa "oficialização" não é, porém, um efeito imediato do modernismo. Como salienta Saraiva, os intelectuais brasileiros negociavam o seu prestígio desde o fim do século XIX. De modo que a conquista desse espaço intelectual fora do Brasil deve ser atribuida também à geração de 1870 , que nutria uma clara aspiração e preocupação para com a sistematização do pensamento brasileiro e, em função disso, realizou o que seria o primeiro grande projeto de interpretação a ter representatividade e projeção em escala nacional com a Revista do Brasil (DE LUCA, 1999, p. 19).

Nesse diapasão, o movimento modernista brasileiro e o desenvolvimento do campo livresco nacional teriam dado continuidade e peso aos propósitos de promover uma revolução cultural no País. Embora essas gerações sejam vistas como esteticamente opostas, vistas de longe, elas ganham uma certa coerência por terem como objetivo comum a transformação do País pela superação de seu atraso orgânico, tanto no que diz respeito ao pensamento (deflagrado pelos abolicionistas), como à organização social (que suscitava condenações à estrutura escravocrata).

Uma visão crítica a respeito das estruturas escravocratas sobre as quais se pautava a sociedade brasileira parece ter sido o motor propulsor do desejo de revolucionar a cultura brasileira a partir de uma reestruturação da sociedade, ainda que essa se processasse mais visivelmente no discurso dos intelectuais do que, de fato, em efetivas propostas de mudança de estrutura social.

Do ponto de vista estético, o modernismo havia incorporado ao fazer literário a linguagem brasileira tanto, na prosa como na poesia, estabelecendo um modelo de instrumento discursivo

\footnotetext{
7 Retirado do Acervo de Ribeiro Couto (seção "Recortes") alocado na Fundação Casa de Rui Barbosa (FCRB). Não foi possivel identificar paginação

8 Dentre os intelectuais que contribuíram para a introdução da literatura brasileira em Portugal e para a formação de uma disciplina dedicada a ela está também Alberto de Oliveira que, assim como Couto, atuou na diplomacia política e literária entre os dois países. Formara-se, assim, uma esfera de leitores críticos para a recepção e o estudo da literatura brasileira em Portugal, um projeto que recebeu anuência de grandes intelectuais da época e a simpatia dos acadêmicos da Faculdade de Letras de Lisboa (SARAIVA, 2004, p. 41-42), completando o gesto de aceitação da cultura e das interpretações que dela fizeram as obras do século XX.
} 
que, em sua forma e expressão, nada tinha de tributável às regras da língua herdada de Portugal.

A incompatibilidade em relação a esse aspecto, conforme atesta Saraiva (2004, p. 47-48), pode ser demonstrada pelas sucessivas tentativas de estabelecer um acordo ortográfico com o Brasil por parte das autoridades portuguesas. A esse respeito interessa-nos um telegrama de Salazar remetido a Ribeiro Couto para agradecer o envio, por parte desse, do romance Cabocla. Nele, o estadista aproveita para expor a sua opinião acerca do estilo linguístico do autor:

\section{Ao Doutor Ribeiro Couto}

Venho agradecer muito penhorado a oferta da Cabocla em primorosíssima edição. Já li uma porção de páginas e tenho gostado muito. Pena é que em geral os pronomes estejam fora do sítio e que alguns complementos de verbos não venham regidos pelas proposições habituais. Mas acabou-se: alguns dos seus compatriotas dizem que estão a fazer outra lingua e bem pode ser que daqui a duzentos anos esses desvios de agora estejam legitimados pelo tempo. Muitos e afectuosos cumprimentos e mais uma vez os melhores agradecimentos pela sua gentileza. De V. Exa. com toda a consideração,

Mto. at ${ }^{\circ}$. ven ${ }^{\circ}$. e obrg ${ }^{\circ}$ 18-1-1946

\section{Oliveira Salazar}

SALAZAR, Oliveira. [Correspondência]. Destinatário: Ribeiro Couto. Portugal, 18 de janeiro de 1946. 1 bilhete.

Apesar do afetuoso agradecimento de Salazar à gentil oferta de Couto, o chefe de Estado português aproveita a oportunidade para tecer comentários com o fito de corrigir os "erros" gramaticais cometidos contra o "bom" português. A alusão à instrumentalização literária de uma "outra língua" - isto é, à corrupção linguística que o livro de Ribeiro Couto opera em relação ao "bom português", assim como a de muitos outros escritores da época -, soa como uma exprobração ao estilo coloquial das obras brasileiras. Embora ele admita que esses desvios poderiam se tornar legitimos no curso do tempo, nessa carta ele subestima o tempo que isso levaria.

A questão ortográfica ainda é assunto central em outra missiva remetida por ele:

\section{Ao Dr. Ribeiro Couto}

Devolvo o telegrama do nosso Dr. Teotónio Pereira. Estimei saber que se considera cada vez mais feliz, decerto no exercício da função e nas relações com o Itamaraty e o Dr. João Neves. A mim queixa-se-me do imenso calor; e eu por minha conta acrescento à temperatura do ambiente e da imprensa que continua de respeito, ainda que um pouco melhor.

Foi uma pena que o "Diário de Notícias" tenha omitido os elogios de ordem pessoal e no caso presente tão importantes. Tinha falado ao Ferro e chamado a atenção para que a paz entre os deuses da filosofia se revelava o único meio eficaz de termos o Vocabulário e com ele a prática da ortografia uniforme.

Logo vi que se ia embaraçar com uma frase da minha carta. Eu devo ter escrito pouco mais ou menos: os jornais vêm hoje (do verbo vir) todos do Brasil. Quero dizer, apresentam-se recheados de notícias do Brasil, não falam senão do Brasil, não parecem saber de mais nada senão do respeita ao Brasil, tomaram todos o gesto, a paixão, o partido do Brasil. Eu talvez devesse ter evitado a construção para um brasileiro que escreveu a Cabocla com pronomes respectivamente fora do lugar. Com a maior consideração, de V. Exa.

Mto. at ${ }^{\circ}$. ven ${ }^{\circ}$. e gr ${ }^{\circ}$

(a) Oliveira Salazar 16/2/1946

SALAZAR, Oliveira. [Correspondência]. Destinatário: Ribeiro Couto. Portugal, 16 de fevereiro de 1946. 1 bilhete.

Como se vê, a língua e a imprensa são os motes centrais desse telegrama. A constância do Brasil nos jornais portugueses parece incomodar o estadista português. Talvez, justamente pela veiculação frequente da imagem brasileira, a questão da ortografia "uniforme" torna-se ainda mais salutar para uma parcela dos intelectuais portugueses que, como Salazar, percebiam a recriação linguística das obras brasileiras como uma corrupção, e até uma profanação, da "última flor do lácio".

Nesse sentido, é significativo recordar que, em outubro de 1945, isto é, poucos meses antes de Salazar remeter seus telegramas a Couto, Brasil e Portugal haviam assinado um acordo ortográfico que visava padronizar o uso da língua portuguesa, diminuindo assim as suas discrepâncias.

Entretanto, apesar de a questão ter sido uma das maiores preocupações do Estado Novo português no que diz respeito à autonomia linguística proclamada pelo Brasil, mesmo assinado por ambas as partes, o acordo acabou por não se consolidar deste lado. Em grande parte, isso se deu porque as mudanças eram maiores para 
os brasileiros do que para os portugueses e, também, porque, por outro lado, submeter-se ao novo código não parecia ser a intenção dos escritores de então que haviam conquistado uma liberdade linguistica que se mostrava, em termos estéticos, popularmente revolucionária, sobretudo, se associarmos a publicação dessas obras às condições de massificação do livro brasileiro - tal como vimos anteriormente -, aliadas a um crescente público leitor, o que fazia com que esses dois processos fossem inconciliáveis.

Mediante essa postura, ressalta-se o fundamento político das sucessivas propostas de acordo cultural e linguístico de Portugal para com o Brasil entre as décadas de 1930 e 1940 diante da sua irrefreável busca por autonomia. $O$ "Acordo cultural luso-brasileiro", assinado em 14 de setembro de 1941, no Palácio do Catete, por António Ferro (Diretor do Secretariado da Propaganda Nacional - SPN) e Lourival Fontes (Diretor do Departamento de Imprensa e Propaganda DIP) pretendeu instituir a colaboração mútua entre intelectuais brasileiros e portugueses. Mas essa diplomacia parece ter sido mais uma manobra do Estado Novo português para estreitar laços com um Brasil em evidência cultural.

O que particularmente extrai-se da carta remetida de Salazar a Couto sobre esse processo é que a partir de suas críticas à linguagem romanesca e à veiculação da imagem do Brasil em Portugal se manifesta um reconhecimento, ainda que a contragosto, de um processo de inversão de predomínio no que diz respeito às referências literárias e culturais no interior dessa comunidade linguística que começava a mostrar-se rica pelas possibilidades expressivas que suscitava em diferentes contextos culturais e literários, dai os intelectuais africanos terem percebido na nova linguagem literária brasileira maiores compatibilidades expressivas do que na língua genuinamente lusitana.

Porventura seria por isso que, alguns anos mais tarde, os intelectuais estadonovistas tenham visto nos escritores e na imagem construida por eles para a nação brasileira, uma forma de recuperar o seu lugar proeminente, projetando sobre o Espelho do Brasil (título de um livro de
José Osório de Oliveira) sua salvação por meio da institucionalização do discurso luso-tropicalista, ainda que não concordassem inteiramente com os discursos culturais oriundos do Brasil moderno. Nesse jogo de representações, o título do livro de José Osório de Oliveira conota a ambiguidade pela qual os escritores brasileiros se veem e são vistos pelos portugueses, incluindo-se aí as distorções que as projeções são capazes de causar.

\section{A adesão dos claridosos}

É, pois, na língua que Osório de Oliveira enxerga, com o estrabismo próprio das lentes imperialistas, a profunda "adjacência" da portugalidade (identidade portuguesa) em Cabo Verde, não apenas em sentido territorial, mas também cultural. Evidenciando a falta de riquezas naturais e a necessidade de estratégias de aprovisionamento de recursos vitais, ele afirma que o arquipélago, pela sua conformação cultural entre africanos e europeus - cuja constituição social se moldou ao pequeno espaço islenho, o que a tornava ainda "mais portuguesa" do que a do Brasil - , é um bem mais cultural do que econômico para Portugal, pela sua baixa taxa de analfabetismo, pelo grau de instrução que apresentam seus habitantes, pelo patriotismo dedicado a Portugal, pela expressão poética depurada (OLIVEIRA, 1931, p. 145).

O principal anseio do crítico português por trás da elaboração desse ensaio que compõe a sua Geografia literária (1931) estaria em revelar aos portugueses da metrópole a existência das ilhas de Cabo Verde por meio de sua expressão literária própria (OLIVEIRA, 1931, p. 137), justificando seu entendimento acerca dela através do contato direto que manteve, enquanto funcionário colonial, com a sociedade do arquipélago e o seu envolvimento direto com aquela intelectualidade.

De fato, José Osório de Oliveira esteve entre os mais ativos divulgadores das literaturas brasileira e cabo-verdiana em Portugal e seu circulo intelectual transatlântico o colocou em uma posição privilegiada para estabelecer diálogos que, a princípio, pareceriam pouco prováveis.

Ao divulgar a literatura brasileira em Portugal, Osório estabeleceu um contato mais íntimo com 
os escritores brasileiros. Particularmente, a sua relação com Ribeiro Couto, outro intelectual fortemente interessado na difusão da literatura brasileira pelo mundo, rendeu uma teia de contatos com os escritores africanos de língua portuguesa, que seriam grandes entusiastas dos modelos literários brasileiros na consolidação de seus próprios sistemas literários, em cujos ramos floresceriam as transformações ou mutações que só seriam permitidas mediante a incorporação de modelos baseados na plasticidade, o que enriqueceu sobremaneira as possibilidades expressivas da língua portuguesa, ao mesmo tempo que expressou as autonomias culturais desses países.

Em se tratando da relação de José Osório de Oliveira com o grupo que seria responsável por instituir o modernismo em Cabo Verde, mais particularmente, ela resultou na travessia de ideias e modelos literários que serviriam às novas preocupações expressivas oficialmente instituídas para o campo literário, em prosa e em poesia, com a criação da revista Claridade, em 1936.

Desde a sua gênese, a revista apresenta inúmeras menções à literatura brasileira, havendo, inclusive, em suas páginas, estudos analíticos que buscam desvendar a composição de romances brasileiros, além de dedicatórias, comparações que tomam obras, autores e, até mesmo, o modelo do hibridismo brasileiro, construido pelo discurso sociológico de Gilberto Freyre, como referência.

Dessa forma, a revista é uma importante fonte de pesquisa para os pesquisadores interessados em abordar a inserção da literatura e da cultura brasileira em outros terrenos longínquos. Essa é, pois, a abordagem proposta aqui, com base no conceito de Franco Moretti (2008) de "distant reading" que propõe um enfoque distanciado de obras literárias, entendendo que ampliar a visão para compreender fenômenos de deslocamento, muitas vezes, também se faz necessário.

O ponto crucial a que se chega é, portanto, compreender no deslocamento dessas obras, as circunstâncias espaço-temporais que sustentaram a elaboração de modelos literários dentro de um ciclo (MORETTI, 2008, p. 31) específico de atualização estética e cultural.
Nesse sentido, é primordial ressaltar que o lançamento da revista Claridade, em 1936, simbolizou uma grande viragem na história da literatura cabo-verdiana. A publicação resultou da união de esforços (inclusive financeiros) de intelectuais locais que se viam presos ao isolamento imposto, de um lado, pela geografia das ilhas e, de outro, pelo jugo colonial.

A necessidade de criar um órgão dissociado da imprensa oficial portuguesa e dos interesses coloniais levou os três idealizadores da revista (Jorge Barbosa, Baltasar Lopes da Silva e Manuel Lopes) a intercederem junto à metrópole pela criação de um jornal. Em pleno período ditatorial, essa intercessão acabou em uma resolução nada favorável ao grupo.

O governo português fixara uma alta quantia como taxa para dificultar e desestimular a criação de uma imprensa divorciada dos interesses da metrópole. Sem condições de efetuar o pagamento, a iniciativa se volta para a criação de uma revista periódica, que seria menos onerosa e igualmente eficaz para a circulação de suas ideias. O grupo claridoso engendrava, assim, um campo intelectual voltado para a difusão da produção erudita dos escritores do arquipélago.

Os nove números publicados da revista compreendem o período de 1936 a 1960. A longevidade da publicação se deve, sobretudo, ao impacto qualitativo dos textos postos em circulação nesse periodo. Um dos maiores trunfos da revista e do grupo claridoso foi o ato de proclamarem a liberdade literária dos escritores islenhos quanto à eleição de novos modelos adequados à sua expressão cultural para reafirmar seu poder de escolha frente às referências que gravitavam o ambiente literário das ilhas. Isso, ressalte-se, em um periodo caracterizado pelas amarras políticas e ideológicas do colonialismo tardio.

A perspectiva adotada nos textos que integram a revista é, essencialmente, comparativa. Observa-se nesse modus operandi dos intelectuais claridosos, o intuito de se fazer ouvir para além de seu lugar de locução. Amparado no circuito literário, mobilizam-se na revista argumentos de integração (discurso que relaciona a cultura cabo-verdiana à matriz cultural portuguesa) e de diferenciação 
(na qual o Brasil é tomado como novo, e outro, parâmetro comparativo), tal como exprime o poeta, um dos próceres do movimento, Jorge Barbosa:

Influência da literatura brasileira teria havido, por certo, nos modernos escritores caboverdianos, que por estas paragens se lançaram na aventura da produção literária, sem amparo, diga-se de passagem sem qualquer estímulo, já não digo material (nem pensar nisso é bom!), mas de compreensão e carinho. Tal influência resultou sobretudo do exemplo dos escritores brasileiros ao se debruçarem sobre a terra natal e sobre a gente irmã, onde foram encontrar os temas das suas obras. Deles aproveitamos, pois, a descoberta e a experiência, que nos contagiaram com o seu entusiasmo de coisa nova. Para mais, havia já parecenças entre o povo de Cabo Verde e grandes sectores do povo brasileiro. [...] O exemplo, repito-o, do ensaísta, do romancista e do poeta modernos brasileiros fez ecoar em nós, com a sua novidade, um ardor novo, e daí advieram novas ideias e a indicação de outros caminhos (BARBOSA, 1953, p. 23-24 apud FERREIRA, 1986, p. XXXI, grifo do autor).

Por outro lado, o forte sentido de enraizamento que perpassa o lema claridoso ("fincar os pés na terra") produziu uma necessidade de conciliação formal que perpassou o sentido do diálogo das novas obras cabo-verdianas em relação às referências externas em gravitação naquele momento.

Nesse sentido, a expressividade das obras brasileiras, vistas em contraste com a norma portuguesa, deram vasão ao bilinguismo cabo- verdiano forjado entre a língua portuguesa e a língua crioula, que passou por um processo de institucionalização após a independência cabo-verdiana, em 1975. Mas mesmo antes desse advento político, atribui-se à Claridade o projeto de legitimar a expressão própria do arquipélago como lingua de criação literária (e, de certa forma, uma língua também protonacionalista, dado que buscava uma representação coletiva), de modo que se pode dizer que a revista é uma publicação bilingue desde a sua gênese e, mais que isso, buscou claramente evidenciar o então "dialeto" crioulo, ao inseri-lo, como parte da expressão artística da revista, na primeira página de sua primeira publicação, lançando a "lantuna \& 2 motivos de finaçom (batuques da ilha de Santi'lago)" como uma espécie de cumprimento ao público cabo-verdiano, que pode então apreciar o processo de consolidação de sua língua marginal em língua nacional e literária.

Portanto, a revista Claridade foi perpassada por relações intelectuais de cooperação transatlântica. ${ }^{9}$ Tal como observa o crítico Manuel Ferreira, no prefácio à edição comemorativa do cinquentenário da revista, os impulsos que deram embasamento à publicação advieram da condensação circunstancial de fatores internos e externos que ele denomina "elementos endógenos e exógenos" (FERREIRA, 1986, p. XXI-XLV). Talvez essa seja a maior evidência do esforço dos escritores claridosos em colocar a literatura cabo-verdiana no (novo) mapa literário da língua portuguesa.

Mais do que uma plataforma para a divulgação dos textos cabo-verdianos, a revista serviu à consolidação do campo intelectual, no sentido preconizado por Pierre Bourdieu (2007), que deu voz aos problemas de Cabo Verde e corpo às preocupações dos intelectuais reunidos em torno dela.

Assim, esses textos não discutem apenas questões de ordem conceitual e estética. Eles buscam, além disso, reunir e amadurecer as formas importadas (ou os "elementos exógenos" a que se refere Manuel Ferreira) para adequá-las à expressão cultural do arquipélago (em uma perspectiva "endógena"), funcionando como uma espécie de receptáculo-catalisador das formas em circulação nas zonas de contato da língua portuguesa, em um processo que, no dizer de Inocência Mata, marcou a "resistência com vista à reinvenção da diferença, que gerou uma intensa cumplicidade com reflexos nas relações pós-coloniais" (MATA, 2013, p. 110).

Em outras palavras, a revista serviu de ponto de confluência às diversas tendências literárias e às novas interpretações sociológicas que

\footnotetext{
9 Ao personificar esse cooperativismo intelectual, Manuel Ferreira cita três principais figuras portuguesas que passaram pelas ilhas entre o fim da década de 1920 e início de 30: Augusto Casimiro (1889-1967). António Pedro (1909-1966) e José Osório de Oliveira (19001964). A complementar as forças externas que interferiram na criação da revista está (em um nivel mais abstrato, mas nem por isso menos incisivo) a "moderna literatura brasileira, nomeadamente a da segunda fase" (FERREIRA, 1986, p. XX-XXI). Se por um lado, o espírito da vanguarda portuguesa se instalava nas ithas disseminando o clima da recepção de novos modelos e incitando a animosidade dos escritores locais; por outro, o encontro com o texto brasileiro se traduzia em "alumbramento" (MELO, 2014, p. 77).
} 
surgiam entre os intelectuais da língua portuguesa. ${ }^{10}$ Ela ofereceu, pois, o espaço necessário para pensar as trocas culturais e simbólicas que corroboraram o desenvolvimento dessa produção erudita que paulatinamente ganhou força e reivindicou a sua autonomia na medida em que instituiu normas próprias para sua produção. Conforme evidencia Pierre Bourdieu:

Pode-se medir o grau de autonomia de um campo de produção erudita com base no poder de que dispõe para definir as normas de sua produção, os critérios de avaliação de seus produtos e, portanto, para retraduzir e reinterpretar todas as determinações externas de acordo com seus princípios próprios de funcionamento (BOURDIEU, 2007, p. 106).

É justamente a conjuntura que caracteriza as relações entre as "determinações externas" e os "princípios próprios de funcionamento" que interessam como pontos de abordagem de uma "distant reading". Por "determinações externas", entendemos tudo o que circula ou é posto em movimento para além de seu espaço de concepção, de modo a integrar um sistema maior de referências literárias e culturais. A literatura brasileira vista de longe se desintegra como algo fechado e voltado para a sua própria conjuntura, suas preocupações expressivas, seus traços distintivos, temáticos e formais para compor um quadro mapeável no qual se torna modelo passivel de apropriação em outro espaço/tempo e cujas implicações reivindicam a atenção dos estudiosos para análises mais apuradas que podem suscitar questões e respostas de uma dimensão conceitual ainda pouco explorada da literatura brasileira.

\section{Considerações finais}

A importância das pesquisas comparadas em lingua portuguesa pode ser sinalizada por trabalhos importantes que demonstram a configuração de um novo mapa literário para os estudos de literatura brasileira comparada, sendo já solidificada a ideia de um rico trânsito literário entre os sistemas literários brasileiros e os africanos de lingua portuguesa. Em Paralelas e tangentes (2003), a pioneira Maria Aparecida Santilli trata dessa circulação, produzindo uma espécie de súmula dos itinerários do livro brasileiro em terras africanas, o que favorece uma perspectiva transatlântica de motivos literários, abrindo um amplo campo aos estudos comparados.

Em "O modelo brasileiro e a literatura moderna cabo-verdiana. Estudo comparado" (2001), Manuel Brito-Semedo ressalta a importância do Brasil para a construção do imaginário da cabo-verdianidade. Em linha similar, Simone Caputo Gomes (2007) e Júlio César Machado de Paula (2009) estudam os efeitos textuais que o modelo literário brasileiro suscitou no meio poético cabo-verdiano.

Ao apreender a literatura brasileira a partir das relações com os africanos, em dois artigos seminais: "Hibridismos indomáveis: possiveis contribuições da obra de Gilberto Freyre para uma teoria pós-colonial lusófona." (2014), e "Antropófagos devorados e seus desencontros: da 'formação' à 'inserção' da literatura brasileira." (2016), Alfredo César Melo trata da importância de se analisar, respectivamente, o impacto e as consequências conceituais causadas pela circulação do livro brasileiro no contexto africano. Tal perspectiva promove um importante reposicionamento dos estudos dedicados à literatura brasileira, uma vez que, pensar a inserção da literatura brasileira (e não a inserção da literatura europeia no Brasil) requer que consideremos, como princípio básico, "as contingências de seus deslocamentos" (MELO, 2016, p. 44).

O que ocorre, portanto, nessa abordagem é uma inversão no sentido sob o qual convencionou-se ler a literatura brasileira. Isso implica "vê-la" distanciada de seus próprios pressupostos sem deixar de compreendê-los como fatores determinantes da adesão que alcançaram entre os escritores africanos de língua portuguesa, em geral, e entre os cabo-verdianos, em especifico. Isso significa também concebê-la para além de si mesma, em um campo que é mais dinâmico quanto às trocas e diverso, sobretudo, do efeito

10 Atente-se para a imbricação, nesse periodo, ainda mais acentuada, entre forma literária e substrato sociológico. Esse aspecto também explica o valor atribuido pelos cabo-verdianos à obra de Gilberto Freyre na esteira da reinterpretação da formação social brasileira (MELO, 2014). 
constrangedor e repreensivo causado por uma perspectiva eurocentrada.

A relação da revista Claridade com as obras e os escritores brasileiros engendrou mais que uma confluência em termos de um ideário estético modernista. Embora esse aspecto interesse muito mais aos estudos da forma, não se pode deixar de lado a importância cultural e até política que essas obras exerceram na construção do pensamento moderno cabo-verdiano.

Certamente, os conceitos estéticos têm crucial importância na análise dos textos claridosos; mas quando postos à luz de uma motivação cultural mais ampla, qual seja, a da busca pela autonomia expressiva do arquipélago em uma conjuntura de amarras sociais e políticas, na expectativa de definir e significar sua especificidade fundada na quimera do hibridismo linguístico e cultural sintetizado entre a cultura africana e a europeia -, esses aspectos tornam-se reagentes tanto no texto literário quanto no próprio ideário da revista, como que trazendo uma luz reativa a elementos que antes eram invisiveis, ou invisibilizados. Eis o efeito refrator que a literatura brasileira foi capaz de causar entre os intelectuais claridosos na primeira metade do século $X X$.

\section{Referências}

BOURDIEU, Pierre. A economia das trocas simbólicas. Introdução, organização e seleção de Sérgio Miceli. São Paulo: Perspectiva, 2007.

BRITO-SEMEDO, Manuel. O modelo brasileiro e a literatura moderna cabo-verdiana. Estudo comparado. África: Revista do Centro de Estudos Africanos, USP, São Paulo, v. 22, n. 23, p. 253-265, 1999/2000/2001.

COUTO, Ribeiro. O instinto do Brasil. A Provincia, 10 de fevereiro de 1929. (Acervo: Fundação Casa de Rui Barbosa (FCRB) - Arquivo-Museu de Literatura Brasileira).

COUTO, Ribeiro. Técnica da ilusão. Jornal do Brasil. Coluna: Projeção literária do Brasil no Estrangeiro, 16 de abril de 1933. (Acervo: Fundação Casa de Rui Barbosa (FCRB) - Arquivo-Museu de Literatura Brasileira).

FERREIRA, Manuel (org., coord. e direção). Claridade: revista de arte e letras. 2. ed. Fac-similar. Linda-a-Velha: A.L.A.C, 1986.

GOMES, Simone Caputo. Cabo Verde e Brasil: um amor pleno e correspondido. O Marrare (UERJ), Rio de Janeiro, n. 9, p. 62-73, 2008.
ESPAGNE, Michel. Sur les limites du comparatisme en histoire culturelle. Genèses: Sciences sociales et histoire (Les objets et les choses), n. 17, p. 112-121, 1994. https:// doi.org/10.3406/genes.1994.1266

HALLEWELL. Laurence. O livro no Brasil: sua história. 2. Ed. revista e ampliada. Trad. Maria da Penha Villalobos, Lólio Lourenço de Oliveira e Geraldo Gerson de Souza. São Paulo: Editora da Universidade de São Paulo, 2005.

LUCA, Tania Regina de. A Revista do Brasil: um diagnóstico para a (N)ação. São Paulo: Fundação Editora da UNESP, 1999

MATA, Inocência. Literatura-mundo em português: encruzilhadas em África. 1616: Anuário de Literatura Comparada, 3, p. 103-118, 2013.

MELO, Alfredo Cesar. Hibridismos indomáveis: possiveis contribuições da obra de Gilberto Freyre para uma teoria pós-colonial lusófona. Luso-Brazilian Review, v. 51, n 1, p. 68-92, 2014. https://doi.org/10.1353/lbr.2014.0003

MELO, Alfredo Cesar. Antropófagos devorados e seus desencontros: da 'formação' à 'inserção' da literatura brasileira. Literatura e Sociedade, v. 21, n. 22, p. 42-54, 2016. https://doi.org/10.11606/issn.2237-1184.voi22p42-54

MORETTI, Franco. Conjecturas sobre a literatura mundial. Trad. José Marcos Macedo. Rev. Novos Estudos, n. 58, p. 173-181, nov. 2000.

MORETTI, Franco. A literatura vista de longe. Trad. Anselmo Pessoa Neto. Porto Alegre: Arquipélago, 2008.

PAULA, Júlio Cesar Machado de Paula. Manuel Bandeira e Claridade: confluências literárias entre o modernismo brasileiro e o cabo-verdiano. 130p. Dissertação (Mestrado) - Departamento de Letras Clássicas e Vernáculas, Universidade de São Paulo, São Paulo, 2005

SALAZAR, Oliveira. [Correspondência]. Destinatário: Ribeiro Couto. Portugal, 18 de janeiro de 1946. 1 bilhete. (Acervo: Fundação Casa de Rui Barbosa (FCRB) - Arquivo-Museu de Literatura Brasileira).

SALAZAR, Oliveira. [Correspondência]. Destinatário: Ribeiro Couto. Portugal, 16 de fevereiro 1946. 1 bilhete. (Acervo: Fundação Casa de Rui Barbosa (FCRB) - Arquivo-Museu de Literatura Brasileira).

SANTIAGO, Silviano. Formação e inserção. O Estado de S. Paulo, 26 maio 2012.

SANTILLI, Maria Aparecida. Paralelas e tangentes: entre literaturas de lingua portuguesa. São Paulo: Arte \& Ciência, 2003.

SARAIVA, Arnaldo. Modernismo brasileiro e modernismo português: subsidios para o seu estudo e para a história das suas relações. Campinas, SP: Editora da Unicamp, 2004

SORÁ, Gustavo. A arte da amizade: José Olympio, o campo de poder e a publicação de obras autenticamente brasileiras. Antropolitica, n. 30, p. 49-71, 2011. 


\section{Bruna Carolina de Almeida Salles}

Doutora em Letras pela Universidade Estadual Paulista - Faculdade de Ciências e Letras de Assis (Unesp), em Assis, SP, Brasil.

\section{Endereço para correspondência}

Bruna Carolina de Almeida Salles

Rua José Sebastião da Rosa, 80

San Fernando Valley, 19800420

Assis, SP, Brasil 